\title{
Socially Just Education: A Theoretical Insight into School Leadership
}

\author{
Dung Nguyen Tri Tran (Corresponding author) \\ Ho Chi Minh City University of Education \\ District 5, Ho Chi Minh City 700000, Vietnam \\ E-mail: dungtran.la@gmail.com
}

Received: Sep. 2, $2021 \quad$ Accepted: Oct. 12, $2021 \quad$ Published: November 1, 2021
doi:10.5296/jse.v11i4.18978 $\quad$ URL: https://doi.org/10.5296/jse.v11i4.18978

\begin{abstract}
The socio-economic changes and neoliberal trends of the twenty-first century have been creating many profound impacts in the education industry, provoking the emerging need for an integrated environment where all individuals and organizations from different classes, backgrounds or communities are expectedly empowered with equal opportunities in order to develop to the fullest. Toward the ideals and goals of social justice in education, the function of leadership practitioners has been strongly challenged and critically redefined for a couple of decades. By theoretically investigating how the global research community has addressed this issue from various angles of view, this article hopes to remind current leaders of educational institutions to grow more sensitive to possible unjust occurrences and build up an inclusive schooling culture by putting learner-related values into the center of their work, addressing existing stereotypes in education, boosting active interactions with socially disadvantaged groups, adopting the perspectives of various stakeholders, as well as delivering other timely administrative reforms during their leadership practices.
\end{abstract}

Keywords: education, leadership, neoliberalism, social justice 


\section{Introduction}

Under the contemporary impact of the market-driven culture, competitiveness, capitalism and other powerful trends of neoliberalism, there have been a wide range of significant alterations in the existence and operation of educational systems worldwide. One of those remarkable changes lies in the reality that schooling can now only achieve its noble objectives in a society where access to high-quality education is equally given to all students irrespective of their social backgrounds (Lingard, 2009). Since global education is now characterized by the pursuit of a socially democratic paradigm, 'the management of institutions has a great importance to achieve the ideal of social justice' (Turhan, 2010, p. 1357). With such a goal in sight, school administrators are accordingly supposed to make necessary changes in the way they interpret and perform their leadership roles.

From a theoretical perspective, this review of the existing literature on social justice leadership aims to provide a profound insight into the responsibilities of school leaders in the contemporary context of education. To be specific, the discussion starts with the explanation of educational leadership in the neoliberal era, and the notion of socially just education is then clarified from various angles of view. Based on this conceptual foundation, the current article goes to explore what school leadership for social justice is like, and finally delivers a number of concrete suggestions to educators who are particularly interested in creating an equitable and inclusive schooling system for the sake of all learners.

\section{Educational Leadership in the Neoliberal Era}

Toward the improvement of schooling experiences and practices, leadership has long been treated as one of the most crucial factors and change agents in the educational sector. Given the twenty-first-century context with all of its diversities and challenges, effective school leadership plays a pivotal role in getting learners well-prepared for all the complexities lurking in the era of global integration. Therefore, the issue of educational leadership has contemporarily captured a large amount of attention from the international community of researchers who have made great efforts to comprehend the nature of leadership under the influence of neoliberalism in education (Lopez \& Rugano, 2018).

\subsection{Conceptual Variances}

According to Adams, Kutty and Zabidi (2017), there are a number of alternatives to the way educational leadership has been defined in the literature. Historically, the professional focus has been shifted over time from administration to management and now from management to leadership (Gunter, 2004; Bush, 2007; Bates, 2010; Eacott, 2013). Whereas administration usually consists of lower order duties, management describes the routine maintenance of present operations and leadership basically involves higher-order tasks aiming to improve the educational performance of staff and students (Dimmock, 1999, as cited in Adams, Kutty, \& Zabidi, 2017, p. 1). At the same time, management can be also seen as a range of actions which are fundamentally linked with the determination of organizational goals (Ghasemy \& Hussin, 2014); and leadership may generally help to yield the maximal level of educational efficiency from both physical and human resources (Bates, 2010). Although there have been 
multiple competing viewpoints and definitions related to educational management and leadership, these two constructs are closely related to each other and equally important toward the achievement of educational excellence and school objectives (Lee \& Dimmock, 1999; Bush, 2007; Ghasemy \& Hussin, 2014).

\subsection{Educational Leadership and Relevant Elements}

Upon the awareness of the relevant terminology, the current article employs educational leadership as the main working term throughout, given the fact that it has actually become one of the most remarkable keywords for the past few decades (Eacott, 2013). As stated by Botha (2013), many continuous reform initiatives have now necessitated the reconstruction of how leadership should be understood, assumed and practiced. From a general perspective, leadership in education is regarded as a high-level activity of setting goals and creating motivation to accomplish them (Lee \& Dimmock, 1999). Based upon clear values and beliefs, this process results in a certain vision which is 'articulated by leaders who seek to gain the commitment of staff and stakeholders to the ideal of a better future for the school, its learners and stakeholders' (Bush, 2007, p. 403). Educational leadership of the neoliberal age necessarily engages with a broad view of the purpose of schooling (Keddie, 2016) and a more contextualized exploration of culture in relation to the achievement of school success (Wrigley, 2008). Inferentially,

school leaders are now responsible for managing the school site, all aspects of school budgets, including staff and equipment, and marketing the school to secure sufficient enrolments in a competitive quasi-market, as well as traditional professional responsibilities for managing the curriculum and learner welfare (Bush, 2016, p. 8).

With their access to power, educational leaders are also believed to be capable of inserting education into political, socio-economic, philosophical and literary discourses which do not only address learners or fellow educators but also involves people of different cultures and ideologies (Bogotch, 2016, as cited in Lopez \& Rugano, 2018, p. 2). Such a sense of complexity about the functioning of school leaders is well reflected in the way Bates (2010) explains the role of leadership in promoting educational processes and the increasing connection between leadership and social demands as well as other political or economic changes. Accordingly, educational leadership is now distributed as a shared responsibility from different parties, and the mechanics of school organization and leadership is no longer seen to be external and indifferent to educational ideals. Indeed, the exercise of educational leadership on a global basis has become more complicated and multi-dimensional as the neoliberal world is putting school leaders in the midst of various challenges and concerns, one of which is about how to insure social justice in the twenty-first-century education.

\section{Conceptualization of Socially Just Education}

\subsection{Social Justice as a General Concern}

Regarding the global interest in the cruelties of neoliberalism (Reay, 2016), there has recently been a great deal of scholarly attention to the matter of social justice. As broadly defined by Rasinski (1987, as cited in Berkovich, 2014, p. 286), this term addresses a value-based belief 
about a lack of opportunities of some social groups in a certain society and how these opportunities are harmfully influenced by current social conditions. However, as an elusive construct which implies the perspectival multiplicity (Shoho, Merchant, \& Lugg, 2005), social justice is frequently interpreted in association with other related concepts, such as disengagement (i.e. personal failure to embrace schooling), inclusion (i.e. allowing disadvantaged people to have full access to life), acceptance (i.e. respecting people who are different from you), or equity (i.e. an emerging reference to fairness which is drawn from economic rationalities and market-driven cultures) (see Keddie, Mills, \& Pendergast, 2011; Capper \& Young, 2014; Lingard, Sellar, \& Savage, 2014; McGregor, 2017 for detailed discussion on these alternative terms). Despite a few variations in the way these concepts have been articulated by scholars, they all share the same major focus on the concerns of those who have to confront inequitable conditions, suffer from unequal social capital and have fewer opportunities than others (Turhan, 2010).

\subsection{Descriptions of Social Justice in Education}

Along with such neoliberal circumstances as the cultural transformation of Western societies, the pressure of high stakes testing as well as the new form of accountability, the actual status of social justice in the education industry is also particularly associated with the gaps of underserved populations (Jean-Marie, Normore, \& Brooks, 2009). Disadvantaged groups in education may include young people from ethnic minorities, low economic backgrounds, the working class or LGBT (lesbian - gay - bisexual - transgendered) community, students labeled with physical disabilities or linguistic diversities, as well as those who fail to conform to academic standards and become undesirably marginalized by the marketized version of schooling (Shoho, Merchant, \& Lugg, 2005; Reay, 2012; Capper \& Young, 2014; Smyth, 2014; McGregor, 2017). While rich students are likely to receive many benefits from the pooling of capital, facilities and resources for maximal productivity, pupils who learn in underprivileged environments have to cope with typically poor educational conditions. As resources are unevenly divided and distributed among schools (Teese, 2007), there is obviously a strong contrast between rich and poor schools, as well as between rich and poor students within a given school. Taking a look into the Australian schooling context as an example, Perry (2018) comes to realize that

educational inequality takes many forms, and is a problem because it stunts the potential of young people. [...] Inequalities between students from different social backgrounds already exist when they start primary school. Worryingly, these inequalities increase as students progress through the education system.

Based on the understanding of how social justice manifests itself in the neoliberal education, the research community has made a large number of efforts to figure out what socially just education is like. Reay (2012, p. 595) describes socially just education as a system premised on the idea that 'a good education is the democratic right of all rather than a prize to be competitively fought over'; and in order to fulfil this maxim, educational systems should take cognizance of socio-economic realities and even call for systemic changes, discursive shifts, social redistribution, as well as curricular innovation. The pursuit of socially just education is, 
therefore, related to educators' efforts to implement pedagogical practices which aim to improve the learning and life opportunities of underserved learners (Ladson-Billings, 1994, as cited in Zembylas \& Bozalek, 2017, p. 2). Embracing the ideology about the intellectually rigorous yet essentially humanizing existence of schools, Smyth (2016) also identifies a number of prominent attributes underlying the socially just education, i.e. promoting success-oriented learning; exploiting the richness of local diversity; seeing disengagement as a curricular issue and disadvantage as a socially constructed matter; improving life opportunities of the most excluded; and regarding leadership as being contingent. Accordingly, socially just education

[...] is committed to producing young people who are literate and numerate, but in addition, it does this in a way in which it inculcates in them the importance of making the world a more just place for all of us (p. 230).

\section{Leadership Practice for Social Justice in Education}

\subsection{Overall Considerations}

In a recent document entitled An Unfair Start: Inequality in Children's Education in Rich Countries, UNICEF Office of Research (2018) reveals the result of their large-scale research covering 41 nations of the European Union and the Organization for Economic Co-operation and Development and affirms the explicit reality that "not all children have an equal opportunity to reach their full potential, to pursue their interests and to develop their talents and skills' (p. 3). Although the manifestation and extent of the issue may vary among societies, those who exercise leadership at their institutions are advised to pay more attention to the existent link between educational inequality and some significant factors including parental occupation, migration background, the learner's gender as well as school characteristics. To be more specific, young children from underprivileged families in half of the European countries have a low attendance rate at preschool. In 35 out of 41 nations under investigation, 15-year-old teenagers whose parents have low-ranked jobs tend to perform badly in reading and show little expectation to complete post-secondary level. Among the 25 places with sufficient data about immigration, there are up to 21 countries where first-generation immigrants are reported to study worse than native-born kids. Regarding the gender factor in relation to reading proficiency, female students in primary schools are likely to gain higher mean scores than male counterparts, and this gap gets even larger when they enter secondary education. Even though gender differences still depend on the countries and subjects, the persistent inequalities between boys and girls can be explained through the balance between male and female teachers, the attitude toward gender as well as the way learners internalize gender norms as they grow up. What is more, educational leaders should also be aware of the variations in average achievement between schools within the same country. One of the many examples mentioned in the report is Hungary where between-school differences occupy approximately one-third of the reading score variation at the primary level and over $50 \%$ of the variation at the secondary level. Indeed, UNICEF Office of Research utilizes the statistics obtained from their survey to raise a strong concern 
for school leaders upon the universal occurrence of injustice across various stages of education.

In today's neoliberal world, any delay in addressing the social injustices at schools is highly likely to result in educational underachievement with a variety of adverse effects on the young generation and even the larger society (Bogotch \& Reyes-Guerra, 2014; Perry, 2018), which consequently requires school leaders to reconsider the way they understand and perform their functions. According to Turhan (2010), social justice leadership basically refers to a social influence which involves the facilitation of moral discourse for affirming relationships with students of all backgrounds and levels by fighting against institutionalized inequalities and injustices within a society. Involving a moral imperative, critical self-reflection as well as action-oriented agenda (Cloninger, 2017), leadership practice for social justice should actually 'go beyond schools and into communities' with the provision of aspiring individuals who do not ignore 'the knowledge and skills needed to address harder truths (i.e. social injustices) beyond the school systems' buildings' (Bogotich \& Reyes-Guerra, 2014, pp. 49-50). In Hesbol's (2013) explanation, the knowledge and skills about which school principals need to be proficient are tightly connected to the four major tenets of a social justice platform, i.e. developing school cultures that include all students (1); insuring literacy for all learners (2); creating the culture of empowerment for positive changes (3); engaging the perspectives of families and the community at the heart of schooling (4).

As schools are now working toward a realistic notion that children must be prepared for participation in a multi-cultural, multi-ability and multi-ethnic society (Jean-Marie, Normore, $\&$ Brooks, 2009), it is very important for education leaders to 'be sensitive to issues of social justice' and 'demonstrate appropriate behaviors' (Turhan, 2010, p. 1360) with a view to making schools more socially integrated (Perry, 2018). As far as socially just leadership is concerned, a great deal of emphasis has been laid on the values of academic achievement, access, equity and opportunity for all students (Hammonds, 2016). At the same time, this new type of educational leadership typically deals with

unequal relationships of power informed by multiple intersectionalities of gender, race, class, ethnicity, religion and sexuality and enacted into practice that is situated within a conjuncture of particular historical, social, political and economic moments (Blackmore, 2018, p. 208).

Socially just leaders are, therefore, expected to take moral responsibility for fostering equitable school processes for the sake of learners who are different from each other in terms of race, gender, culture, socio-economy or sexual orientations (Evans, 2007, as cited in Jean-Marie, Normore, \& Brooks, 2009, p. 4).

\subsection{Further Implications for School Leaders}

In an attempt to add a more practical sense to this whole investigation into social justice leadership in education, a critical synthesis of both qualitative and quantitative studies (including Berkovich, 2014; Capper \& Young, 2014; Smyth, 2014; UNICEF Office of Research, 2018; Zhang, Goddard, \& Jakubiec, 2018) has been done, disclosing six main 
recommendations for leadership practitioners who might be finding themselves in a struggle for an equitable and democratic educational environment.

Table 1. A systematic summary of some concrete leadership behaviors for socially just education

\section{Facets}

\section{Specifications}

Pursuit of fundamental principles of social justice in education
It is generally advisable for educational leaders to guarantee a fair start for all children with both equalities and averages, challenge gender stereotypes, reduce the segregation of children from different backgrounds, and insure their achievement of core skills required by the twenty-first-century society.
Adoption of a socio-ecological perspective to social justice
Contemporary school leaders need to understand about their role as social activists who focus on the practice of power sharing and value-based dialog abilities via enthusiastic interaction with those whose lives are adversely affected by the workingsi of neoliberalism.
Perception of leadership goals
As advocates of socially just education, school leadlers ought to consider student learning and success as the central goal of their work and must be fully aware of the wide range of learner differences and intersections, so that they are able to effectively construct inclusive communities of practice for all children.
Significant role of initiative and networking
Because the responsibility of a school principal for social justice is not at all the matter of a single individual, aspiring leaders should be more proactive in practicing their relational leadership skills and take part in networking forums where they can powerfully reinforce their initiatives and strengthen their moral agency.
Correlation between leadership for social justice and community context
Since the idea about socially just education requires a thorough understanding from a large population, successful principalship entails responsiveness to the context where the school is located (i.e. a net of school leaders, teachers, learners, parents as well as other people from communities) and awareness of how this multi-layered social environment influences leadership actions. 


\section{Macrothink $\Lambda$ Institutem}

Other

administrative

considerations
As the bureaucratic legislation, administrative regulations and ethical codes unquestionably play a substantial part in supporting the social justice ethos and guiding the relevant actions of educational leaders, these factors ought to be approached in a thorough, tactical and strategic fashion.

Only when these commitments are satisfactorily enacted and fulfilled can school leaders believe in an optimistic future of education where students from hybrid backgrounds are all engaged in an equitable and inclusive setting. Once again, leadership for social justice in education is certainly a multi-dimensional notion and places plenty of requirements on the part of educational leaders who essentially need to make informed changes in the way they conceptualize and exercise their roles under the impact of various neoliberal trends.

\section{Final Words}

All in all, there have been a great number of intensive discussions on the responsibilities of school leaders to guarantee equality in different contexts (Turhan, 2010). Via a thorough review of the global discourse on leadership for socially just education, the significance of social justice ideology is highlighted in this article as one of the most influential factors to shape school leadership practice in the twenty-first-century setting. Social justice leadership is firmly grounded in the belief in the moral values of equity in today"s culturally hybrid education and tightly related to the creation of equal opportunities for all people who come from different backgrounds, especially those belonging to poorly marginalized groups. In the face of many neoliberal trends confronting schooling systems around the world, current leaders of educational institutions need to optimize necessary resources and get well prepared for the increasingly diverse needs of students by promoting a secure space which desirably reflects professional integrity, academic excellence as well as socio-cultural equity. As in an interesting metaphor by Jean-Marie, Normore and Brooks (2009, p. 4), school leaders should now treat themselves as 'the architects and builders of a new social order' wherein disadvantaged groups have the same educational and social opportunities as traditionally advantaged people. Challenging as this may seem, effective conduct of social justice leadership can surely help to reduce educational underachievement and make schools a better place for all learning individuals to enjoy their experiences and improve their outcomes.

\section{References}

Adams, D., Kutty, G. R., \& Zabidi, Z. M. (2017). Educational leadership for the $21^{\text {st }}$ century. International Online Journal of Educational Leadership, 1(1), 1-4. https://doi.org/10.22452/iojel.vol1no1.1

Bates, R. (2010). History of educational leadership/management. In P. L. Peterson, E. L. Baker, \& B. McGraw (Eds.), International encyclopedia of education (pp. 724-730). Oxford: Elsevier Science. 
Berkovich, I. (2014). A socio-ecological framework of social justice leadership in education. $\begin{array}{llll}\text { Journal of } & \text { Educational } & \text { Administration, } & \text { 52(3), }\end{array}$ https://doi.org/10.1108/JEA-12-2012-0131

Blackmore, J. (2018). Leadership as a relational practice in contexts of cultural hybridity. In J. Wilkinson \& L. Bristol (Eds.), Educational Leadership as a Culturally-Constructed Practice (pp. 208-216). New York: Routledge.

Bogotch, I., \& Reyes-Guerra, D. (2014). Leadership for social justice: Social justice pedagogies. Revista Internacional de Educación para la Justicia Social, 3(2), 33-58.

Botha, R. J. (2013). Epistemological beliefs and leadership approaches among South African school principals. Educational Studies, 39(4), 431-443. https://doi.org/10.1080/03055698.2013.776944

Bush, T. (2007). Educational leadership and management: theory, policy, and practice. South African Journal of Education, 27(3), 391-406.

Bush, T. (2016). School leadership and management in England: The paradox of simultaneous centralisation and decentralisation. Research in Educational Administration \& Leadership, 1(1), 1-23. https://doi.org/10.30828/real/2016.1.1

Capper, C. A., \& Young, M. D. (2014). Ironies and limitations of educational leadership for social justice: A call to social justice educators. Theory Into Practice, 53(2), 158-164. https://doi.org/10.1080/00405841.2014.885814

Cloninger, K. L. (2017). Leading for social justice: A qualitative study of school principals in Washington State. Doctoral dissertation, Washington State University, U.S.A. Retrieved from https://research.libraries.wsu.edu/xmlui/handle/2376/12960

Eacott, S. (2013). Rethinking 'leadership' in education: a research agenda. Journal of Educational Administration and History, 45(2), 113-125. https://doi.org/10.1080/00220620.2013.768971

Ghasemy, M., \& Hussin, S. (2014). A review of theories of educational management and leadership. Paper presented at Seminar Kebangsaan Majlis Dekan-Dekan Pendidikan IPTA 2014, 25-26 September 2014, University of Malaya, Malaysia. Retrieved from https://www.researchgate.net/publication/300048835_Theories_of_Educational_Management _and_Leadership_A_Review

Gunter, H. (2004). Labels and labelling in the field of educational leadership. Discourse: Studies in the Cultural Politics of Education, 25(1), 21-41. https://doi.org/10.1080/0159630042000178464

Hammonds, H. L. (2016). Leadership in diverse schools: An examination of early college high school principals in North Carolina. Diversity, Social Justice \& the Educational Leadership, 1(1), 13-25. 
Hesbol, K. A. (2013). Preparing leaders to reculture schools as inclusive communities of practice. In L. C. Tillman \& J. J. Scheurich (Eds.), Handbook of Research on Educational Leadership for Equity and Diversity (pp. 603-624). New York: Routledge.

Jean-Marie, G., Normore, A. H., \& Brooks, J. S. (2009). Leadership for social justice: Preparing $21^{\text {st }}$ century school leaders for a new social order. Journal of Research on Leadership Education, 4(1), 1-31. https://doi.org/10.1177/194277510900400102

Keddie, A. (2016). School autonomy as 'the way of the future': Issues of equity, public purpose and moral leadership. Educational Management Administration \& Leadership, 44(5), 713-727. https://doi.org/10.1177/1741143214559231

Keddie, A., Mills, M., \& Pendergast, D. (2011). Fabricating an identity in neo-liberal times: Performing schooling as 'number one'. Oxford Review of Education, 37(1), 75-92. https://doi.org/10.1080/03054985.2010.538528

Lee, J. C., \& Dimmock, C. (1999). Curriculum leadership and management in secondary schools: a Hong Kong case study. School Leadership \& Management, 19(4), 455-481. https://doi.org/10.1080/13632439968970

Lingard, B. (2009, November). Testing times: The need for new intelligent accountabilities for schooling. QTU Professional Magazine, 24, 13-19.

Lingard, B., Sellar, S., \& Savage, G. C. (2014). Re-articulating social justice as equity in schooling policy: The effects of testing and data infrastructures. British Journal of Sociology of Education, 35(5), 710-730. https://doi.org/10.1080/01425692.2014.919846

Lopez, A. E., \& Rugano, P. (2018). Educational leadership in post-colonial contexts: What can we learn from the experiences of three female principals in Kenyan secondary schools? Education Sciences, 8(3). https://doi.org/10.3390/educsci8030099

McGregor, G. (2017). Counter-narratives that challenge neo-liberal discourses of schooling 'disengagement': Youth professionals informing the work of teachers. British Journal of Sociology of Education, 38(4), 551-565. https://doi.org/10.1080/01425692.2015.1113859

Perry, L. (2018, April 20). To reduce inequality in Australian schools, make them less socially segregated. The Conversation. Retrieved from $\mathrm{http}$ //theconversation.com/to-reduce-inequality-in-australian-schools-make-them-less-sociall y-segregated-95034

Reay, D. (2012). What would a socially just education system look like?: Saving the minnows from the pike. Journal of Education Policy, 27(5), 587-599. https://doi.org/10.1080/02680939.2012.710015

Reay, D. (2016). How possible is socially just education under neo-liberal capitalism? Struggling against the tide? Forum, 58(3), 325-330. https://doi.org/10.15730/forum.2016.58.3.325 
Shoho, A. R., Merchant, B. M., \& Lugg, C. A. (2005). Social justice: Seeking a common language. In F. W. English (Ed.), The SAGE Handbook of Educational Leadership (pp. 47-67). Thousand Oaks, California: SAGE Publications.

Smyth, J. (2014). Improving schools in poor areas: It's not about the organisation, structures and privatisation, stupid! Improving Schools, 17(3), 231-240. https://doi.org/10.1177/1365480214556418

Smyth, J. (2016). Space, place and neighborhood in the pursuit of the "socially just school". In A. Montgomery \& I. Kehoe (Eds.), Reimagining the Purpose of Schools and Educational Organisations (pp. 221-232). Cham, Switzerland: Springer.

Teese, R. (2007). Time and space in the reproduction of educational inequality. In R. Teese, S. Lamb, \& M. Duru-Bellat (Eds.), International Studies in Educational Inequality, Theory and Policy (pp. 1-21). Dordrecht: Springer.

Turhan, M. (2010). Social justice leadership: Implications for roles and responsibilities of school administrators. Procedia - Social and Behavioral Sciences, 9(2010), 1357-1361. https://doi.org/10.1016/j.sbspro.2010.12.334

UNICEF Office of Research (2018). An unfair start: Inequality in children's education in rich countries. Innocenti Report Card 15. Retrieved from https://www.unicef-irc.org/publications/995-an-unfair-start-education-inequality-children.ht $\mathrm{ml}$

Wrigley, T. (2008). School improvement in a neo-liberal world. Journal of Educational Administration and History, 40(2), 129-148. https://doi.org/10.1080/00220620802210905

Zembylas, M., \& Bozalek, V. (2017). Re-imagining socially just pedagogies in higher education: The contribution of contemporary theoretical perspectives. Education as Change, 21(2), 1-5. https://doi.org/10.17159/1947-9417/2017/3051

Zhang, Y., Goddard, J. T., \& Jakubiec, B. A. E. (2018). Social justice leadership in education: A suggested questionnaire. Research in Educational Administration \& Leadership, 3(1), 53-86. https://doi.org/10.30828/real/2018.1.3 